\title{
Topotecan Hydrochloride Liposomes
}

National Cancer Institute

\section{Source}

National Cancer Institute. Topotecan Hydrochloride Liposomes. NCI Thesaurus. Code C80065.

The hydrochloride salt of a semisynthetic derivative of camptothecin mixed with sphing omyelin/cholesterol and sonicated to form small unilamellar vesicles containing topotecan, with potential antineoplastic activity. Topotecan hydrochloride liposomes mediates efficient drug delivery of topotecan into the cytosol from the endosome compartment. During the S phase of the cell cycle, topotecan selectively stabilizes topoisomerase I-DNA covalent complexes, inhibiting religation of topoisomerase Imediated sing le-strand DNA breaks and producing potentially lethal double-strand DNA breaks when complexes are encountered by the DNA replication machinery. 